\title{
Relationships Between Musical Structure and Psychophysiological Measures of Emotion
}

\author{
Patrick Gomez and Brigitta Danuser \\ Institut Universitaire Romand de Santé au Travail
}

\begin{abstract}
Psychophysiological studies with music have not examined what exactly in the music might be responsible for the observed physiological phenomena. The authors explored the relationships between 11 structural features of 16 musical excerpts and both self-reports of felt pleasantness and arousal and different physiological measures (respiration, skin conductance, heart rate). Overall, the relationships between musical features and experienced emotions corresponded well with those known between musical structure and perceived emotions. This suggests that the internal structure of the music played a primary role in the induction of the emotions in comparison to extramusical factors. Mode, harmonic complexity, and rhythmic articulation best differentiated between negative and positive valence, whereas tempo, accentuation, and rhythmic articulation best discriminated high arousal from low arousal. Tempo, accentuation, and rhythmic articulation were the features that most strongly correlated with physiological measures. Music that induced faster breathing and higher minute ventilation, skin conductance, and heart rate was fast, accentuated, and staccato. This finding corroborates the contention that rhythmic aspects are the major determinants of physiological responses to music.
\end{abstract}

Keywords: music, emotion, respiration, heart rate, skin conductance

In music research, a distinction is generally made between perceived emotions and felt emotions. This distinction is based on the idea that music may both represent emotions (that are perceived by listeners) and induce emotions (that are felt by listeners). Perceived and experienced emotion may not always coincide (Gabrielsson, 2002). The two cases may involve different psychological mechanisms and, as suggested by Harrer and Harrer (1968), be associated with different physiological correlates. Several researchers have investigated the relationships between musical structure and perceived emotions (reviewed by Gabrielsson \& Juslin, 2003, and Gabrielsson \& Lindström, 2001), but, to our knowledge, the relationships between musical structure and experienced emotions have never been studied. It is important to develop a taxonomy of music-induced emotions and to explore how they relate to the internal structure of the music.

Researchers interested in establishing the link between musical features and emotion have largely concentrated on verbal reports of feeling, ignoring other components of emotion, notably physiological changes. Other researchers have investigated the correspondence between self-reports and physiological responses but have not examined, or at least derived hypotheses about, what exactly in the music might have been responsible for the observed physiological phenomena.

Patrick Gomez and Brigitta Danuser, Institut Universtitaire Romand de Santé au Travail, Lausanne, Switzerland.

We thank Jelena Bulavko, Neringa Balnytè-Rittner, and Felix Escher for the technical analysis of the musical excerpts and Alice De Batz for her statistical advice.

Correspondence concerning this article should be addressed to Patrick Gomez, Institut Universtitaire Romand de Santé au Travail, Rue du Bugnon 19, Lausanne, Switzerland CH-1005. E-mail: patrick.gomez@hospvd.ch
To our knowledge, very few reports exist on this subject, and some of them suffer from methodological shortcomings. Destunis and Seebrandt (1958) related physiological changes to the "dominating" element of the music (e.g., pronounced rhythmics in Stravinsky's "Le Sacre du Printemps") but did not consider other structural features. Traxel and Wrede (1959) classified their excerpts as either symphonic, entertaining, or rhythmically accentuated but did not analyze the musical structure in detail. Kneutgen (1970) reported that the breathing became synchronized with a lullaby reproduced repeatedly for a time span of up to $2 \mathrm{hr}$ (1 measure $=1$ breath) and the heart rate decreased, yet no information about tempo or other structural features was given. Wilson and Aiken (1977) failed to find any differences in skin conductance responses to rock music played at two different sound intensities (79 and $95 \mathrm{~dB}$ ). Allesch (1981) reported a tendency of the breathing rate to be higher during rhythmically accentuated passages than during lyric-meditative passages of "Atom Heart Mother" by Pink Floyd, but no more systematic analyses were conducted. Frank (1982) found an increase in the number of synchronizations in the sense of a coordination in integral ratios $(1: 1,1: 2,2: 3)$ between musical rhythm and heart rate (compared with a situation without music) more often when the musical rhythm approached the spontaneous heart rate. Harrer (1982) reported a progressive acceleration of heart rate and breathing rate with increasing tempo in "In the Hall of the Mountain King" by Edvard Grieg and an increase in heart rate while listening to an accelerating metronome. In a study by Schmidt (1984), three jazz titles were played in four different tempi $(70,140,210, \& 280 \mathrm{bpm})$ to three groups of participants. With increasing tempo, skin conductance level (SCL), heart rate (HR), and respiratory rate increased, as well as the subjective arousal, but not the evaluation of pleasantness. However, the article did not include a statistical analysis, nor was it clear whether the reports of arousal and pleasantness referred to 
the perceived or the felt emotions. Haas, Distenfeld, and Axen (1986) reported a significant correlation between musical rhythm and total breath duration. Vaitl, Vehrs, and Sternagel (1993) found that skin conductance responses were larger during passages of slow tempi than fast tempi of the leitmotivs of Wagner's opera "The Mastersingers of Nuremberg" in 3 participants. However, other musical features were not analyzed in detail.

The only sound conclusion that one can draw from the reviewed literature is that increasing tempo seems to be accompanied by increasing breathing rate and HR. Reports for skin conductance are inconclusive.

In this study, we explored the relationships between several structural features of the music and both self-reports of experienced pleasantness and arousal and different physiological measures (respiratory parameters, skin conductance, HR). The dimensions of valence (pleasantness) and arousal (activation) are pervasive organizers of the subjective response (e.g., Bradley \& Lang, 1994) and the somatophysiological response (e.g., Gomez, Stahel, \& Danuser, 2004; Lang, Greenwald, Bradley, \& Hamm, 1993) to a wide range of affective stimuli. This two-dimensional structure of emotion has also been found for music both at the level of subjective responses (e.g., Faith \& Thayer, 2001; also, see Gabrielsson \& Juslin, 2003, for a review) and of physiological activity (Gomez \& Danuser, 2004a; Nyklíček, Thayer, \& Van Doornen, 1997; Witvliet, 1998) indicating that valence and arousal are fundamental dimensions of musical emotions. The article is based on a previous study (Gomez \& Danuser, 2004a), in which we investigated the relationships between the subjective response and the physiological response to music and noises. Here, the same affective rating data and physiological data are put in relation with the structure of the musical excerpts.

The goals were to determine the extent to which the relationships between musical features and experienced emotions correspond with those known between musical structure and perceived emotions. Furthermore, we were interested in determining which structural aspects of the music are the major determinants of experienced pleasantness and arousal, as well as of the different physiological parameters. We believe that studies like this can help elucidate how music leads to certain psychophysiological phenomena and, in this way, help explain how music can modify our behavior or determine how music can effectively be used for therapeutic purposes or in the workplace.

\section{Method}

\section{Participants}

The participants were 16 men and 15 women, ranging in age from 18 to 37 years ( $M=24$ years). They reported no long-term hearing impairment and were healthy on the day of testing.

A questionnaire was used to assess musical habits, preferences, and training. Most participants were good consumers of music, with 20 of them reporting that they listened to music often (about $50 \%$ of the time being at home awake) to very often (more than $75 \%$ ) and only 3 reporting that they listened rarely (less than 10\%). Pop, rock, and classical music were the music styles participants listened to most frequently. No participant reported disliking classical music. All but 4 participants reported having received formal training on one or more instruments or voice. On average, these participants had taken 6.6 years of musical instruction.

\section{Stimuli}

Participants listened to 16 noises and 16 musical fragments with a duration of $30 \mathrm{~s}$ each. The musical excerpts were all instrumental and were drawn from the corpus of Western music; they are listed in Table 1 (see Note). The stimuli were presented over a pair of speakers. The noise and musical stimuli were presented in a mixed order (see Gomez \& Danuser, 2004a, for details on the presentation order).

\section{Subjective and Physiological Response Measurements}

The subjective and physiological response measurements were as reported in Gomez and Danuser (2004a). Self-reports of valence and arousal were registered using the pencil-and-paper version of the 9-point Self-Assessment Manikin (SAM; Bradley \& Lang, 1994). Respiration was measured using a respiratory inductive plethysmograph (Respitrace PLUS, SensorMedics, NIMS [NonInvasive Monitoring Systems], North Bay Village, FL). For each breath, the following respiratory parameters were extracted: inspiratory time (Ti) and expiratory time (Te, including expiratory pause), inspiratory volume ( $\mathrm{Vi}$ ) and expiratory volume (Ve), and the percentage of rib cage contribution to $\mathrm{Vi}(\% \mathrm{RC})$. Minute ventilation $(\mathrm{MV}$; inspiratory volume/total breath duration, expressed in $\mathrm{L} / \mathrm{min}$ ) was calculated off-line. Only Vi was used as a measure of tidal volume. Skin conductance level (SCL) and heart rate (HR) were measured with the Varioport Measurement System (Becker Meditec, Karlsruhe, Germany). Refer to Gomez and Danuser (2004a) for details on calibration procedures and data recordings.

\section{Procedure}

The procedure was as reported in Gomez and Danuser (2004a). In short, participants were tested individually in a sound-insulated room. They were presented with 16 noises and 16 musical passages of 30-s duration. After each stimulus, they reported how they felt while listening to the stimulus using the SAM and then relaxed for about $65 \mathrm{~s}$ until the next stimulus.

\section{Technical Description of the Musical Selections}

The selection of the musical features was based on previous work (see Gabrielsson \& Juslin, 2003, and Gabrielsson \& Lindström, 2001). Eleven musical features were assessed for each musical excerpt. Ten features were judged by three musical experts using 7-point rating scales ranging as follows for each feature: tempo $(1=$ slow, 7 = fast $)$, rhythm $(1=$ outstanding, $7=$ vague $)$, accentuation $(1=$ light, $7=$ marcato $)$, rhythmic articulation $(1=$ staccato, $7=$ legato $)$, pitch level $(1=$ low, $7=$ high $)$, pitch range $(1=$ narrow, $7=$ wide $)$, melodic direction $(1=$ ascending, $7=$ descending $)$, mode $(1=$ minor, $7=$ major $)$, harmonic complexity $(1=$ simple, $7=$ complex $)$, and consonance $(1=$ dissonant, $7=$ consonant). The 11th feature was sound intensity, for which the equivalent sound level (Leq) was assessed with a sound-level meter and expressed in $\mathrm{dB}(\mathrm{A})$.

The three musical experts were a professional singer and graduate in musicology, a professional pianist, and a student of musicology in his fourth year of course. During their first visit to the laboratory, they individually rated all excerpts in all musical as- 
Table 1

Technical Characteristics of the Musical Selections

\begin{tabular}{|c|c|c|c|c|c|c|c|c|c|c|c|}
\hline $\begin{array}{l}\text { Musical } \\
\text { selection }\end{array}$ & $\begin{array}{l}\text { Sound } \\
\text { intensity }\end{array}$ & Tempo & Rhythm & Accentuation & $\begin{array}{l}\text { Rhythmic } \\
\text { articulation }\end{array}$ & $\begin{array}{l}\text { Melodic } \\
\text { direction }\end{array}$ & $\begin{array}{l}\text { Pitch } \\
\text { level }\end{array}$ & $\begin{array}{l}\text { Pitch } \\
\text { range }\end{array}$ & Mode & Complexity & Consonance \\
\hline 1 & 67.6 & 6.3 & 1.7 & 7.0 & 2.0 & 4.0 & 5.0 & 3.0 & 6.3 & 3.0 & 6.3 \\
\hline 2 & 69.7 & 6.3 & 1.3 & 6.3 & 3.0 & 2.0 & 5.7 & 5.7 & 7.0 & 2.0 & 6.3 \\
\hline 3 & 62.2 & 4.3 & 2.7 & 4.0 & 3.0 & 3.7 & 4.0 & 2.0 & 6.3 & 2.0 & 5.3 \\
\hline 4 & 66.0 & 4.7 & 2.7 & 5.0 & 4.3 & 5.0 & 4.7 & 5.3 & 6.3 & 3.7 & 5.3 \\
\hline 5 & 61.0 & 2.7 & 2.0 & 3.0 & 6.7 & 3.7 & 5.7 & 6.0 & 6.0 & 2.0 & 6.3 \\
\hline 6 & 66.7 & 2.0 & 2.7 & 3.0 & 5.3 & 4.0 & 5.0 & 2.3 & 5.3 & 3.3 & 5.3 \\
\hline 7 & 71.8 & 5.0 & 6.0 & 5.3 & 5.0 & 2.7 & 2.7 & 4.7 & 1.3 & 6.3 & 3.0 \\
\hline 8 & 65.2 & 3.3 & 2.7 & 6.0 & 4.0 & 4.7 & 3.3 & 3.0 & 1.7 & 3.3 & 2.7 \\
\hline 9 & 68.6 & 2.0 & 2.3 & 2.7 & 7.0 & 2.7 & 3.3 & 4.0 & 6.0 & 2.3 & 6.3 \\
\hline 10 & 61.9 & 3.7 & 3.0 & 4.0 & 5.3 & 3.7 & 4.0 & 4.3 & 5.0 & 4.0 & 5.3 \\
\hline 11 & 65.1 & 2.7 & 5.3 & 2.7 & 5.3 & 3.0 & 5.0 & 4.0 & 1.3 & 2.0 & 5.7 \\
\hline 12 & 77.5 & 7.0 & 5.7 & 6.7 & 4.7 & 3.3 & 2.0 & 5.3 & $\underline{-}^{\mathrm{a}}$ & 4.3 & 3.0 \\
\hline 13 & 73.1 & 2.3 & 3.7 & 5.7 & 6.7 & 1.0 & 6.3 & 5.7 & 3.0 & 4.3 & 4.3 \\
\hline 14 & 67.7 & 2.0 & 1.7 & 2.3 & 6.7 & 3.0 & 4.0 & 3.7 & 2.7 & 4.7 & 4.7 \\
\hline 15 & 62.3 & 1.7 & 5.0 & 2.7 & 6.7 & 2.0 & 4.7 & 3.3 & 5.7 & 4.3 & 5.0 \\
\hline 16 & 58.9 & 2.3 & 2.0 & 2.0 & 7.0 & 3.0 & 4.7 & 2.3 & 6.0 & 2.7 & 6.0 \\
\hline
\end{tabular}

Note. The musical selections were as follows: 1. Offenbach-Rosenthal, Cancan; 2. A. Ponchielli, La Gioconda-Dance of the Hours; 3. E. Serra, Le Grand Bleu-Spaghetti del Mare; 4. G. Mahler, Symphony No. 1, Langsam Schleppend; 5. E. Elgar, Salut d'Amour; 6. G. Holst, The Planets-Venus; 7. R. Strauss, Also sprach Zarathustra-Von den Freuden und Leidenschaften; 8. E. Serra, Le Grand Bleu-The Monastery of Amorgos; 9 . A. Dvorák, Symphony No. 9-Largo; 10. E. Elgar, Enigma Variations-Romanza; 11. Gandalf, From Source to Sea-Refuge Island; 12. Manowar, Hail to England-Black Arrows; 13. S. Barber, Adagio for strings Op. 11; 14. D. Borgir, Puritanical Euphoric Misanthropia-Fear and Wonder; 15. G. Mahler, Symphony No. 5-Adagietto; 16. M. Ravel, Piano Concerto in G major-Adagio assai. All musical features, except sound intensity [rated in $\mathrm{dB}(\mathrm{A})]$ were rated on a scale ranging from 1 to 7 . For tempo, 1 = slow and 7 = fast; for rhythm, $1=$ outstanding and 7 = vague; for accentuation, $1=$ light and $7=$ marcato; for rhythmic articulation, $1=$ staccato and $7=$ legato; for pitch level, $1=$ low and $7=$ high; for pitch range, $1=$ narrow and $7=$ wide; for melodic direction, $1=$ ascending and $7=$ descending; for mode, $1=$ minor and $7=$ major; for harmonic complexity, $1=$ simple and $7=$ complex; for consonance, $1=$ dissonant and $7=$ consonant.

${ }^{\text {a }}$ Selection 12 was an atonal guitar solo.

pects. A week later, they were invited to the laboratory a second time to rate and discuss together those technical features in which we identified disagreement. Disagreement was considered to be present when the difference between the highest and the lowest rating was of 3 or more scale points (e.g., 4 and 7). In all but four cases, a consensus (i.e., difference between the highest and the lowest rating of 2 or fewer scale points) was found. The intraclass correlation coefficients (Shrout \& Fleiss, 1979) were as follows: tempo, 0.87; rhythm, 0.63; accentuation, 0.77; rhythmic articulation, 0.79; melodic direction, 0.55 ; pitch level, 0.65; pitch range, 0.71; mode, 0.84; complexity, 0.61; and consonance, 0.66.

\section{Data Reduction}

For all physiological parameters, median values of the 15-s interval before stimulus onset (baseline) and median values of the 15 -s interval before stimulus offset (stimulus interval) were computed for each participant and each stimulus. The median values of the baselines and of the stimulus intervals were log-transformed to minimize skewness and heteroscedasticity. Then, response scores were calculated by subtracting the transformed baseline score from the transformed score of the stimulus interval. The experts' ratings for each musical feature were averaged, and the means were used in the statistical analyses.

\section{Statistical Analyses}

Musical features in the affective space. Valence and arousal define a two-dimensional affective space (Russell \& Feldman
Barrett, 1999). With this analysis, we aimed to establish the distribution of the different musical features in the affective space in order to determine the structural characteristics of musical passages that had induced positive high-arousal, positive lowarousal, negative high-arousal, and negative low-arousal emotions (the four quadrants of the affective space). Previous research has generally looked at the relation between musical features and valence and between musical features and arousal separately. However, the two components combine in an integral fashion so that, subjectively, a person has one feeling rather than, for example, unpleasant and, separately, deactivated. The relation between one affective dimension and a musical feature may depend on the level of the other dimension. Thus, it is important to use an analytic strategy that correlates the structural features of the music with the ratings of valence and arousal simultaneously.

The analytic approach used is similar to the one reported by Gomez, Stahel, \& Danuser (2004; Analysis 2). For each participant separately, the model $Y=\alpha+\beta_{V} V+\beta_{A} A+\beta_{V A} V^{*} A+E$ was fitted. $Y$ is the musical feature, $V$ and $A$ are the subjective valence and arousal judgments given by the participants, and $E$ is the random error parameter. When the interaction between valence and arousal was not significant, the model without the interaction term was tested. The coefficients (slope) $\beta_{V}, \beta_{A}$, and $\beta_{V A}$ were estimated for each participant separately, and these numbers were tested by Wilcoxon signed-ranks test against the null hypothesis of symmetry around zero. Statistical significance was evaluated at the 0.05 level. The median of the participants' coefficients was used as estimation of the effect. 
Musical features and physiology. We assessed the relationships between the musical features and the following physiological variables: Ti, Te, Vi, MV, \%RC, SCL, and HR. For each participant separately, the model $Y=\alpha+\beta_{M} M+\beta_{M M} M * M+E$ was fitted. $Y$ is the response score of the physiological measures as defined above. $M$ is the musical feature (e.g., tempo), and $E$ is the random error parameter. When the quadratic component $(M * M)$ was not significant, the model with only the linear component $(M)$ was tested. The coefficients $\beta_{M}$ and $\beta_{M M}$ were estimated for each participant separately, and these numbers were tested by Wilcoxon signed-ranks test against the null hypothesis of symmetry around zero. Statistical significance was evaluated at the 0.05 level. The median of the participants' coefficients was used as estimation of the effect.

\section{Results}

\section{Musical Features}

Characterization and distribution across the 16 selections. Table 1 presents the sound intensity levels and the means of the experts' ratings of the musical features for the 16 excerpts. As revealed by Table 2 , the musical features were not equally well represented on the 7-point rating scale. Tempo, accentuation, and pitch range showed a good distribution. Rhythm, pitch level, and harmonic complexity were slightly shifted to one pole of the scale: Few excerpts had a vague rhythm and a low pitch level, and only one selection had a highly complex harmony. As expected, mode was bipolarized with a slight predominance of major mode. Legato selections exceeded staccato pieces. No excerpts had a clearly descending melody, and most selections were consonant.

Correlation between musical features. Strong linear correlations were obtained between tempo and accentuation (Pearson $r=$ $.84)$, tempo and rhythmic articulation $(r=-.79)$, and accentuation and rhythmic articulation $(r=-.72)$, indicating that increasing tempo was associated with more marcato accentuation and more staccato articulation. A Pearson $|r|>.70$ was also obtained between consonance and complexity $(r=-.71)$ and between consonance and mode $(r=.76)$, indicating that more consonant harmonies were simpler and more often in a major mode. Analyses with a general linear model indicated two highly significant qua- dratic relationships between pitch level and sound intensity and between pitch level and pitch range: Both low-pitched and highpitched excerpts were louder and had a wider pitch range than medium-pitched selections.

\section{Relationships Between Musical Features and Felt Valence and Arousal}

The estimated models for the 11 musical features are presented in Table 3. Sound intensity is represented in Figure 1A. The plot shows that sound intensity was lowest for positive low-arousal excerpts and highest for negative high-arousal excerpts. Tempo was faster for positive than for negative excerpts and for higharousal than for low-arousal excerpts (Figure 1A). The rhythm tended to be more vague for negative high-arousal excerpts with more outstanding rhythms for the other three quadrants of the affective space (Figure 1A). Increasing arousal was associated with more accentuated rhythms. Rhythmic articulation was more staccato for positive than for negative excerpts and for higharousal than for low-arousal excerpts. Increasing pleasantness was associated with descending melodies, and high-arousal excerpts had a lower pitch than low-arousal excerpts. The pitch range was wider for negative high-arousal excerpts with narrower ranges in the other three quadrants (Figure 1B). Negative high-arousal selections were more often in minor mode, and positive high-arousal selections were more often in major mode (Figure 1B). Harmonic complexity was higher for negative than for positive selections and for high-arousal than low-arousal selections. Consonance decreased from the positive low-arousal to the negative high-arousal excerpts (Figure 1B).

How different were the structural characteristics of the musical passages that induced negative low-arousal, negative high-arousal, positive low-arousal, and positive high-arousal emotions? Using the estimated models, we calculated the values of each musical feature for the following four pairs of values of valence $(\mathrm{V})$ and arousal (A), each representing the "center" of one quadrant of the affective space: Negative low-arousal (NL) V = 3, A = 3; negative high-arousal $(\mathrm{NH}) \mathrm{V}=3, \mathrm{~A}=7$; positive low-arousal ( $\mathrm{PL}$ ) $\mathrm{V}=7, \mathrm{~A}=3$; positive high-arousal $(\mathrm{PH}) \mathrm{V}=7, \mathrm{~A}=7$. The values are presented in Table 4. The mean differences of these

Table 2

Means, Standard Deviations, 33.3 and 66.6 Percentiles, Minimum and Maximum Values for the 11 Musical Features

\begin{tabular}{|c|c|c|c|c|c|c|}
\hline Musical feature & $M$ & $S D$ & $\begin{array}{c}33.3 \\
\text { Percentile }\end{array}$ & $\begin{array}{c}66.6 \\
\text { Percentile }\end{array}$ & Minimum & Maximum \\
\hline Sound intensity & 66.6 & 4.9 & 64.6 & 67.8 & 58.9 & 77.5 \\
\hline Tempo & 3.65 & 1.76 & 2.33 & 4.39 & 1.67 & 7.00 \\
\hline Rhythm & 3.15 & 1.52 & 2.28 & 3.10 & 1.33 & 6.00 \\
\hline Accentuation & 4.27 & 1.71 & 2.94 & 5.39 & 2.00 & 7.00 \\
\hline Rhythmic articulation & 5.17 & 1.58 & 4.61 & 6.67 & 2.00 & 7.00 \\
\hline Melodic direction & 3.21 & 1.02 & 2.94 & 3.67 & 1.00 & 5.00 \\
\hline Pitch level & 4.37 & 1.15 & 4.00 & 5.00 & 2.00 & 6.33 \\
\hline Pitch range & 4.04 & 1.31 & 3.28 & 4.77 & 2.00 & 6.00 \\
\hline Mode & 4.67 & 2.05 & 3.99 & 6.00 & 1.33 & 7.00 \\
\hline Complexity & 3.40 & 1.24 & 2.61 & 4.05 & 2.00 & 6.33 \\
\hline Consonance & 5.06 & 1.24 & 4.94 & 5.72 & 2.67 & 6.33 \\
\hline
\end{tabular}

Note. Sound intensity in $\mathrm{dB}(\mathrm{A})$. The other musical features were rated on a scale from 1 to 7 . 
Table 3

Medians of the Estimated Regression Coefficients $\beta_{V}$ (Valence), $\beta_{A}$ (Arousal), and $\beta_{V A}$ (Valence $\times$ Arousal) for the 11 Musical Features

\begin{tabular}{|c|c|c|c|c|}
\hline Musical feature & Constant & $\begin{array}{l}\text { Valence estimate } \\
\text { coefficient }\end{array}$ & $\begin{array}{l}\text { Arousal estimate } \\
\text { coefficient }\end{array}$ & $\begin{array}{l}\text { Valence } \times \text { Arousal } \\
\text { estimate coefficient }\end{array}$ \\
\hline Sound intensity & $58.40(13.77)$ & $0.50(2.05)$ & $2.14^{* * * *}(2.10)$ & $-0.18^{* *}(0.30)$ \\
\hline Tempo & $1.20(1.40)$ & $0.10^{* *}(0.22)$ & $0.43^{* * * *}(0.16)$ & \\
\hline Rhythm & $2.23(4.21)$ & $0.16^{*}(0.74)$ & $0.35^{* *}(0.91)$ & $-0.05^{* *}(0.15)$ \\
\hline Accentuation & $2.24(1.31)$ & $0.00(0.13)$ & $0.46^{* * * * *}(0.11)$ & \\
\hline Rhythmic articulation & $7.92(1.91)$ & $-0.26^{* * *}(0.23)$ & $-0.33^{* * * * *}(0.18)$ & \\
\hline Melodic direction & $2.69(1.16)$ & $0.12^{* * * *}(0.16)$ & $0.00(0.11)$ & \\
\hline Pitch level & $4.54(0.72)$ & $0.05(0.11)$ & $-0.07^{* * *}(0.07)$ & \\
\hline Pitch range & $2.17(2.04)$ & $0.22^{*}(0.25)$ & $0.37^{* * * *}(0.48)$ & $-0.05^{*}(0.09)$ \\
\hline Mode & $6.40(3.44)$ & $-0.27^{*}(0.64)$ & $-0.71^{* *}(1.26)$ & $0.11^{* * * *}(0.18)$ \\
\hline Complexity & $4.17(1.23)$ & $-0.19^{* * * * *}(0.15)$ & $0.07^{* *}(0.15)$ & \\
\hline Consonance & $5.80(2.32)$ & $0.01(0.36)$ & $-0.37^{\text {*** }}(0.58)$ & $0.04^{* *}(0.10)$ \\
\hline
\end{tabular}

Note. Interquartile ranges are in parentheses.

${ }^{*} p<.05 .{ }^{* *} p<.01 .^{* * * *} p<.001 .^{* * * * *} p<.00001$ (Wilcoxon signed rank test against the null hypothesis of symmetry around zero).

values between each pair of quadrants across all musical features (except sound intensity) were as follows: PH-PL, 0.60; PH-NH, 0.70; PH-NL, 0.83; PL-NH, 0.98; PL-NL, 0.35; and NH-NL, 0.97. Thus, the largest difference was between the positive low-arousal quadrant and the negative high-arousal quadrant, and the smallest difference was between the positive low-arousal quadrant and the negative low-arousal quadrant. The mean difference between positive and negative excerpts was 0.52 and between high-arousal and low-arousal 0.78 .

\section{Relationships Between Musical Features and Physiological Responses}

Significant linear and quadratic relationships are reported in Table 5 .

Linear relationships. Tempo, accentuation, and rhythmic articulation were linearly related to $\mathrm{Ti}, \mathrm{Te}, \mathrm{MV}$, and SCL: Faster tempo, more accentuated, and more staccato excerpts were associated with shorter Ti and Te, larger MV, and higher SCL. Faster tempo was also related to higher HR, whereas the relations between HR and accentuation and rhythmic articulation approached the significance level. Increases in sound intensity were associated with a shortening of Te and an increase in SCL. A wider pitch range was accompanied by higher SCL.

Quadratic relationships. Ti showed quadratic relationships with rhythm, pitch range, mode, complexity, and consonance. They are represented in Figure 2 (upper left). Quadratic trends were obtained for Te and MV with rhythm, mode, complexity, and consonance (Figure 2, upper right and lower left). A quadratic relationship was found for SCL with rhythm, pitch level, and consonance (Figure 2, lower right) and for HR with mode. In interpreting the graphs of Figure 2, it is important to consider the actual ranges of the musical features reported in Table 2. The graphs show that $\mathrm{Ti}$ and $\mathrm{Te}$ were shortest for very outstanding and very vague rhythms, in clear examples of major and minor mode, for excerpts with a simple harmony, and for both consonant and dissonant selections. MV was highest for outstanding rhythms, for excerpts in major mode, and for complex and dissonant harmonies. SCL was highest for vague rhythms, for low-pitched excerpts, and for both consonant and dissonant selections. HR was highest for major mode excerpts.

\section{Discussion}

\section{Musical Structure and the Affective Space}

All musical features analyzed were significantly related to felt pleasantness and/or arousal. This suggests that the musical features analyzed were important in discriminating the subjective emotional experience. However, not all features were equally important. Melodic direction and pitch level varied modestly along the valence and the arousal dimension, respectively. Melodic direction and pitch level are two of the musical features that have the least clear associations with specific emotional expressions (Gabrielsson \& Lindström, 2001; Hevner, 1937; Thompson \& Robitaille, 1992; Watson, 1942). In contrast, other features markedly differentiated the two affective dimensions. The three musical features with the most important contribution to distinguishing between negative and positive excerpts were mode, rhythmic articulation, and harmonic complexity. The three musical features contributing most importantly to distinguish between low-arousal and high-arousal excerpts were accentuation, tempo, and rhythmic articulation. Research on perceived arousal suggests that loudness is a major predictor of arousal (Schubert, 1999); in the present study, it is difficult to evaluate its relative importance because of the different unit of measurement.

On the whole, a large number of similarities emerged when we compared the relations obtained here between musical structure and experienced emotions and those between musical structure and perceived emotions. High arousal and positive valence were associated with fast tempo as it is suggested by the literature on emotional expression (e.g., Dalla Bella, Peretz, Rousseau, \& Gosselin, 2001; Hevner, 1937; Thompson \& Robitaille, 1992; Watson, 1942). A good correspondence was also found for mode, sound intensity, rhythmic articulation, complexity, and consonance. The major mode-positive valence and minor mode-negative valence associations (e.g., Dalla Bella, Peretz, Rousseau, \& Gosselin, 2001; Kleinen, 1968) were largely confirmed in the present study. 
A Sound intensity

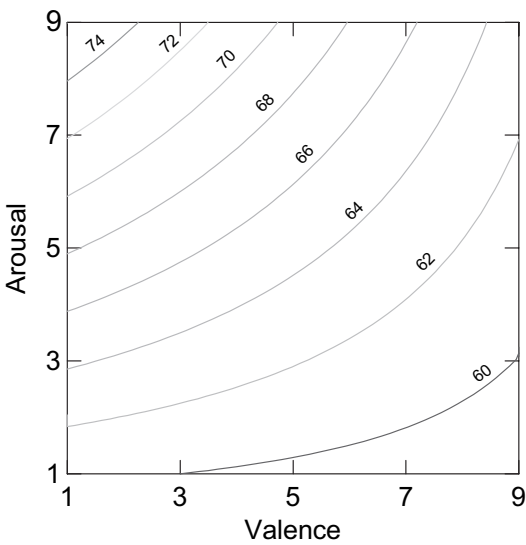

B

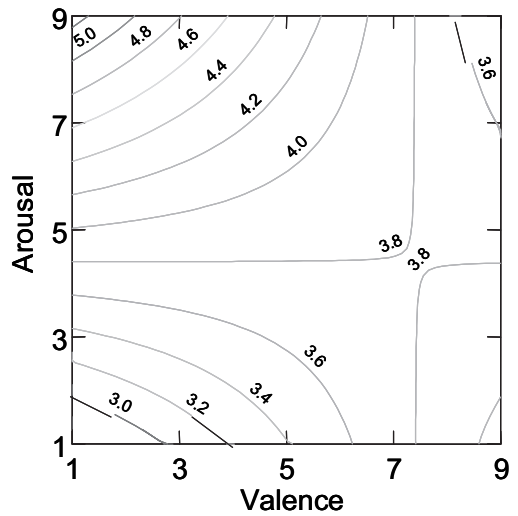

Tempo

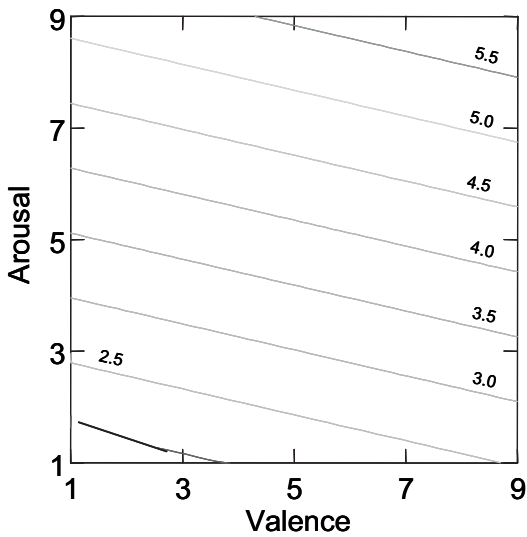

Mode

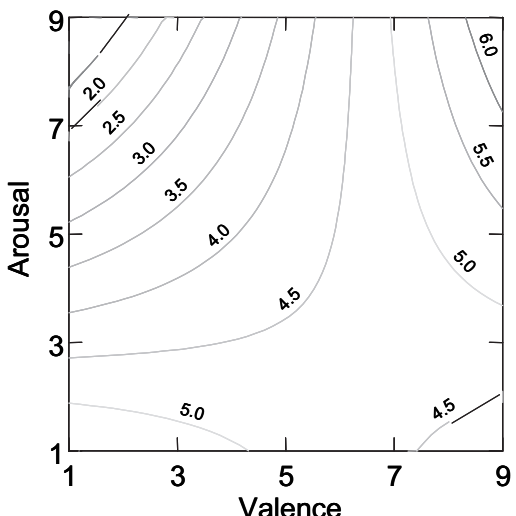

Rhythm

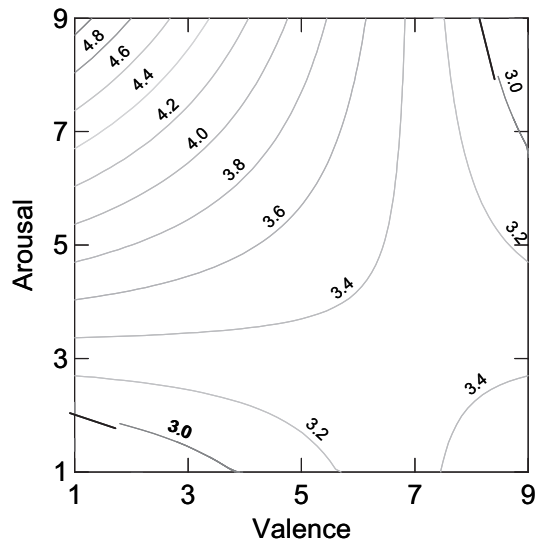

Consonance

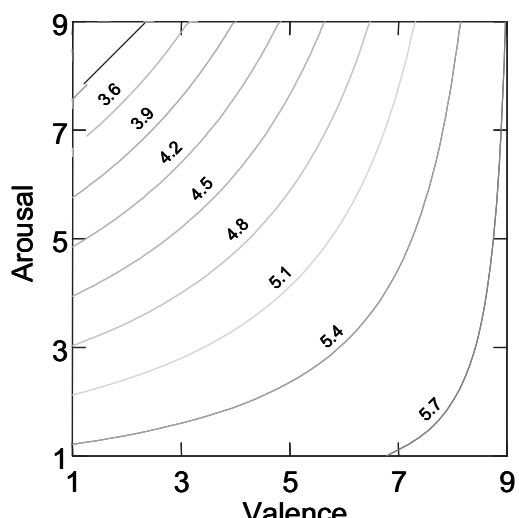

Figure 1. (A) Sound intensity, tempo, and rhythm in the affective space defined by valence and arousal. On the $x$ - and $y$-axes, $1=$ most negative valence/lowest arousal and $9=$ most positive valence/highest arousal. The estimated models represented are as follows: sound intensity, or $\mathrm{dB}(\mathrm{A})=58.40+2.14 \times$ arousal $-0.18 \times$ valence $\times$ arousal; tempo $=1.20+0.10 \times$ valence $+0.43 \times$ arousal; rhythm $=2.23+0.16 \times$ valence + $0.35 \times$ arousal $-0.05 \times$ valence $\times$ arousal. Tempo was rated on a scale ranging from 1 (slow) to 7 (fast), and rhythm was rated on a scale ranging from 1 (outstanding) to 7 (vague). $\quad$ (B) Pitch range, mode, and consonance in the affective space defined by valence and arousal. On the $x$ - and $y$-axes: $1=$ most negative valence/lowest arousal and $9=$ most positive valence/highest arousal. The estimated models represented are as follows: pitch range $=2.17+0.22 \times$ valence $+0.37 \times$ arousal $-0.05 \times$ valence $\times$ arousal; mode $=6.40-0.27 \times$ valence $0.71 \times$ arousal $+0.11 \times$ valence $\times$ arousal; consonance $=5.80-0.37 \times$ arousal $+0.04 \times$ valence $\times$ arousal. Pitch range was rated on a scale ranging from 1 (narrow) to 7 (wide), mode was rated on a scale ranging from 1 (minor) to 7 (major), and consonance was rated on a scale ranging from 1 (dissonant) to 7 (consonant).

Sound intensity, which has been shown to correlate positively with arousal (Juslin, 1997; Rigg, 1964; Watson, 1942), was higher for high-arousal emotions than for low-arousal emotions. The association between staccato articulation and high arousal and between legato articulation and low arousal suggested by studies on emotional expression (Juslin, 1997; Rigg, 1964; Wedin, 1972) was clearly observed here as well. The statement by Gabrielsson and Juslin (2003) that, in general, "positive valence apt to consonance and simple harmony, high arousal may be dissonant and contain more complex harmony" (p. 520) can be well applied to our findings.

When people judge emotional expression in music, they (should) focus on the music as an object and are expected to suppress the influence of personal and situational factors. On the contrary, when it comes to one's own experiences, personal and situational factors have free access and may have as much, or even more, influence on our responses than the music itself. The results of this study suggest that the internal structure of the music played 
Table 4

Representative Values of the 11 Musical Features for the Four Quadrants of the Affective Space

\begin{tabular}{|c|c|c|c|c|c|c|}
\hline \multirow[b]{2}{*}{ Musical feature } & \multicolumn{4}{|c|}{ Quadrants of the affective space } & \multirow[b]{2}{*}{ Valence effect } & \multirow[b]{2}{*}{ Arousal effect } \\
\hline & $\begin{array}{c}\text { Negative } \\
\text { low arousal }\end{array}$ & $\begin{array}{c}\text { Negative } \\
\text { high arousal }\end{array}$ & $\begin{array}{c}\text { Positive } \\
\text { low arousal }\end{array}$ & $\begin{array}{c}\text { Positive } \\
\text { high arousal }\end{array}$ & & \\
\hline Sound intensity & 63.2 & 69.6 & 61.0 & 64.6 & 3.6 & 5.0 \\
\hline Tempo & 2.8 & 4.5 & 3.2 & 4.9 & 0.4 & 1.7 \\
\hline Rhythm & 3.3 & 4.1 & 3.3 & 3.3 & 0.4 & 0.4 \\
\hline Accentuation & 3.6 & 5.5 & 3.6 & 5.5 & 0.0 & 1.9 \\
\hline Rhythmic articulation & 6.1 & 4.8 & 5.1 & 3.8 & 1.0 & 1.3 \\
\hline Melodic direction & 3.0 & 3.0 & 3.4 & 3.4 & 0.4 & 0.0 \\
\hline Pitch level & 4.3 & 4.1 & 4.3 & 4.1 & 0.0 & 0.2 \\
\hline Pitch range & 3.5 & 4.4 & 3.8 & 3.9 & 0.4 & 0.5 \\
\hline Mode & 4.5 & 2.9 & 4.7 & 4.9 & 1.1 & 0.9 \\
\hline Complexity & 3.8 & 4.1 & 3.0 & 3.3 & 0.8 & 0.3 \\
\hline Consonance & 5.1 & 4.1 & 5.5 & 5.2 & 0.7 & 0.6 \\
\hline
\end{tabular}

Note. The values reported are for the following pairs of values of valence $(\mathrm{V})$ and arousal (A), each representing the "center" of one quadrant: Positive high-arousal $\mathrm{V}=7, \mathrm{~A}=7$; positive low-arousal $\mathrm{V}=7, \mathrm{~A}=3$; negative high-arousal $\mathrm{V}=3, \mathrm{~A}=7$; negative low-arousal $\mathrm{V}=3$, $\mathrm{A}=3$. The values were calculated using the estimated models reported in Table 3. Valence effect is the absolute value of the difference between the negative and the positive quadrants; arousal effect is the absolute value of the difference between the low-arousal and the high-arousal quadrants. Sound intensity is in $\mathrm{dB}(\mathrm{A})$, the other musical features were rated on a scale ranging from 1 to 7.

a primary role in the induction of the emotions in comparison with extramusical factors. The study further suggests that it may be more so for the feeling of arousal than the feeling of valence. In fact, the musical features differentiated more clearly between low-arousal and high-arousal emotions than between negative and positive emotions. This reflects the higher consistency in the arousal reports than in the valence reports across participants (see Gomez \& Danuser, 2004a). Particularly small were the differences in the musical structure between the negative low-arousal and positive low-arousal quadrants. This is consistent with studies on emotional expression showing difficulty in the discrimination of positive low-arousal (e.g., tenderness) and negative low-arousal (e.g., sadness) emotions (Campbell, 1942; Gabrielsson \& Juslin, 1996; Juslin, 1997; Thompson \& Robitaille, 1992). Situational and personal factors may be decisive in the recognition and experience of these feelings.

Musical structure is believed to express and induce emotions through iconic relationships (Sloboda \& Juslin, 2001). Iconic relationships come about through some formal resemblance between a musical structure and some nonmusical event or agent carrying emotional "tone" (e.g., the human voice; Dowling \& Harwood, 1986). The association between musical features that carry valence information and their nonmusical referents might be more easily modifiable by individual factors than the association between musical features that carry arousal information and their nonmusical referents. Fast and loud music shares features with events of high energy and so suggests a high-energy emotion. In fact, tempo is not limited to music; the rate of events in time characterizes many human behaviors (e.g., gait, speech). Walking faster or speaking faster is associated with more energy expenditure. Similarly, a louder sound carries more energy than a softer one and to produce a louder sound with the voice requires more energy than to produce a softer sound. The association between musical features such as fast tempo and high loudness and events of high energy is consistent with the idea that music possesses qualities that Stern (1985) has named vitality affects. Concerning two major determinants of valence-mode and consonancestudies show a late emergence of sensitivity to mode (Dalla Bella, Peretz, Rousseau, \& Gosselin, 2001), much later than sensitivity to tempo (Baruch \& Drake, 1997), consistent with the idea that sensitivity to mode may be more dependent on individual learning through exposure to the music of our Western culture. Although there might be in the infant a biological preparedness that makes consonance more attractive than dissonance (Zentner \& Kagan, 1998), the concept of consonance/dissonance is culturally conditioned; thus, its link with feelings of pleasantness may be largely modulated by individual experience.

Despite the wordings in the instructions, one could wonder whether the participants in fact reported the recognized emotional expression rather than how they felt themselves, or whether they mixed these two alternatives. In reality, the border between perception and induction of emotions is somewhat blurred (see Gabrielsson, 2002). More research is needed on the distinction between emotion perception and induction and, more generally, on the impact of the attitude to the music adopted by the listener (so-called listening types). Neurophysiological research could help in this undertaking. It has been suggested that perception of emotion is associated with the right brain hemisphere, whereas induction of emotion is lateralized according to valence of emotion (Oatley \& Jenkins, 1996). Furthermore, Harrer and Harrer (1968) have observed that analytical listening is accompanied by much less activation of the autonomic nervous system compared with a situation in which the participant is invited to experience emotions. It is interesting that they have reported a certain activation even when the participant does not pay attention to the music, which points to an autonomic processing of musical information (see Kölsch, Schroger, \& Gunter, 2002).

\section{Musical Structure and the Physiological Variables}

The physiological responses to music depended on the different structural characteristics of the musical fragments. In particular, 
Table 5

Medians of the Estimated Regression Coefficients $\beta_{M}$ (Linear Term) and $\beta_{M M}$ (Quadratic Term) for the Physiological Variables

\begin{tabular}{|c|c|c|c|}
\hline $\begin{array}{l}\text { Physiological } \\
\text { variable }\end{array}$ & $\begin{array}{l}\text { Musical } \\
\text { features }\end{array}$ & $\begin{array}{l}\text { Estimate coefficient of } \\
\text { the linear term }\end{array}$ & $\begin{array}{l}\text { Estimate coefficient of } \\
\text { the quadratic term }\end{array}$ \\
\hline $\mathrm{Ti}$ & $\begin{array}{l}\text { Tempo } \\
\text { Rhythm } \\
\text { Accentuation } \\
\text { Articulation } \\
\text { Pitch range } \\
\text { Mode } \\
\text { Complexity } \\
\text { Consonance }\end{array}$ & $\begin{array}{c}-9.0^{* * * *}(20.0) \\
61.1^{* * *}(157.6) \\
-7.7^{* *}(20.5) \\
8.9^{* * *}(26.9) \\
60.8^{* * *}(156.1) \\
56.9^{* * *}(86.0) \\
60.3^{*}(140.6) \\
78.8^{* * *}(165.4)\end{array}$ & $\begin{array}{l}-8.8^{* * *}(19.3) \\
-6.4^{* * *}(18.9) \\
-7.9^{* * * *}(12.9) \\
-4.2^{*}(18.3) \\
-9.3^{* * *}(19.4)\end{array}$ \\
\hline $\mathrm{Te}$ & $\begin{array}{l}\text { Sound intensity } \\
\text { Tempo } \\
\text { Rhythm } \\
\text { Accentuation } \\
\text { Articulation } \\
\text { Mode } \\
\text { Complexity } \\
\text { Consonance }\end{array}$ & $\begin{array}{c}-1.5^{\text {*** }}(5.8) \\
-13.9^{* * * *}(23.0) \\
70.2^{* * *}(146.4) \\
-8.7^{* * * *}(19.0) \\
12.6^{* *}(28.0) \\
61.5^{* *}(126.5) \\
47.6^{* * *}(110.5) \\
115.1^{* *}(234.7)\end{array}$ & $\begin{array}{l}-8.3^{* *}(20.9) \\
-7.9^{* * * *}(15.7) \\
-3.9^{* *}(16.5) \\
-12.5^{* *}(27.0)\end{array}$ \\
\hline MV & $\begin{array}{l}\text { Tempo } \\
\text { Rhythm } \\
\text { Accentuation } \\
\text { Articulation } \\
\text { Mode } \\
\text { Complexity } \\
\text { Consonance }\end{array}$ & $\begin{array}{c}10.9^{\text {** }}(21.0) \\
-86.8^{* * *}(118.2) \\
8.2^{* *}(13.5) \\
-8.5^{* *}(20.8) \\
-55.8^{* * *}(112.9) \\
-57.7^{* *}(77.1) \\
-117.8^{* * *}(140.0)\end{array}$ & $\begin{array}{l}8.2^{* * *}(17.3) \\
9.5^{* * * *}(14.3) \\
8.1^{* * *}(12.8) \\
12.4^{* * *}(15.7)\end{array}$ \\
\hline SCL & $\begin{array}{l}\text { Sound intensity } \\
\text { Tempo } \\
\text { Rhythm } \\
\text { Accentuation } \\
\text { Articulation } \\
\text { Pitch level } \\
\text { Pitch range } \\
\text { Consonance }\end{array}$ & $\begin{array}{c}1.8^{* * * * *}(1.9) \\
3.9^{* * * * *}(5.1) \\
-6.0^{* *}(33.8) \\
4.0^{* * * *}(5.6) \\
-1.4^{* *}(6.3) \\
-41.6^{* * * *}(49.9) \\
3.8^{* *}(7.2) \\
-28.8^{* *}(70.1)\end{array}$ & $\begin{array}{l}1.7^{* * * *}(4.9) \\
4.6^{* * * *}(5.5) \\
3.4^{* * *}(7.1)\end{array}$ \\
\hline HR & $\begin{array}{l}\text { Tempo } \\
\text { Mode }\end{array}$ & $\begin{aligned} 1.9^{*}(5.3) \\
-9.1^{*}(26.4)\end{aligned}$ & $1.5^{* * *}(3.1)$ \\
\hline
\end{tabular}

Note. Interquartile ranges are in parentheses. $\mathrm{Ti}=$ inspiratory time; $\mathrm{Te}=$ expiratory time; $\mathrm{MV}=$ minute ventilation; $\mathrm{SCL}=$ skin conductance level; $\mathrm{HR}=$ heart rate.

${ }^{*} p<.05{ }^{* * *} p<.01 .^{* * * *} p<.001 .^{* * * * *} p<.00001$.

faster tempo and more accentuated and staccato rhythms were associated with shorter Ti and Te, larger MV, and higher SCL. These results confirm our expectations based on previous reports (Haas, Distenfeld, \& Axen, 1986; Harrer, 1982; Kneutgen, 1970; Schmidt, 1984). Faster tempo was also associated with higher HR in accordance with other studies (Darner, 1966; Frank, 1982; Harrer, 1982; Schmidt, 1984). These findings corroborate the idea that rhythm is a major determinant of (some) physiological responses to music. Rhythm is the primary element of all music (Hodges, 1996), and rhythm is a fundamental life process. Our bodies operate on rhythmic patterns, and these rhythmic patterns can be modified by external rhythms (Byers, 1976). Rhythmic drumming at certain frequencies can make the brain's rhythms become synchronized to them (Rosenfeld, 1985). The tendency for synchronization of internal biophysiological oscillators to external auditory rhythms likely represents an important explanatory venue for the emotion-inducing effect of music.
Despite a correlation between tempo and arousal and contrary to the other physiological measures, HR did not vary along the arousal dimension (Gomez \& Danuser, 2004a). One should notice, however, that the correlation between HR and tempo was only marginally significant, and this may explain the apparent contradiction. Some important differences between this study and the cited studies should also be acknowledged: In Harrer's (1982) report, the relation between HR and tempo was observed within a music piece and with a metronome when the tempo progressively accelerated; that is, in the unfolding of the music across time. In Schmidt's (1984) study, the tempo differences between the musical selections were huge (from 70 to $280 \mathrm{bpm}$ ), and Darner (1966) exposed himself to sound pulses over weeks before observing enduring increases and decreases in HR. Vi was unrelated to all musical features consistent with the lack of any relationship with reports of valence and arousal (Gomez \& Danuser, 2004a). Independent of the affective tone of the music, Vi decreased from 
Inspiratory time (Ti)

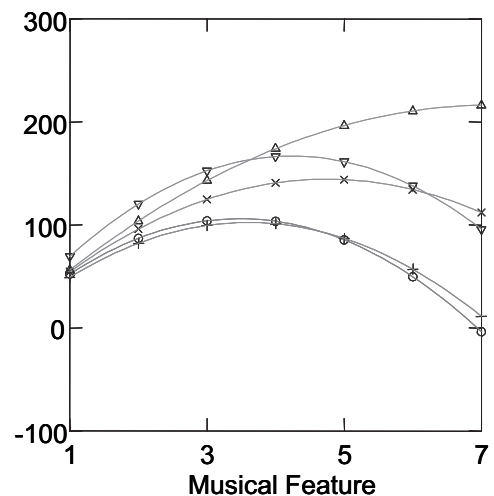

Minute ventilation (MV)

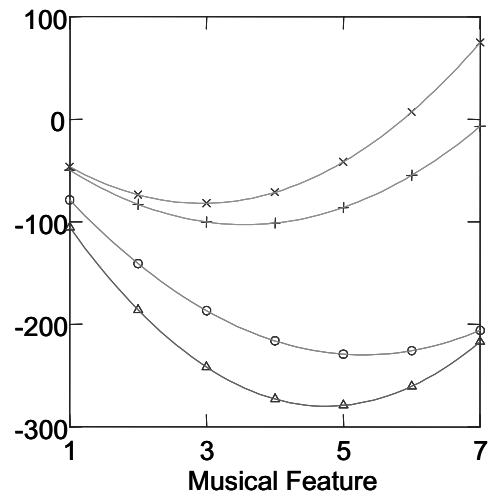

Expiratory time (Te)

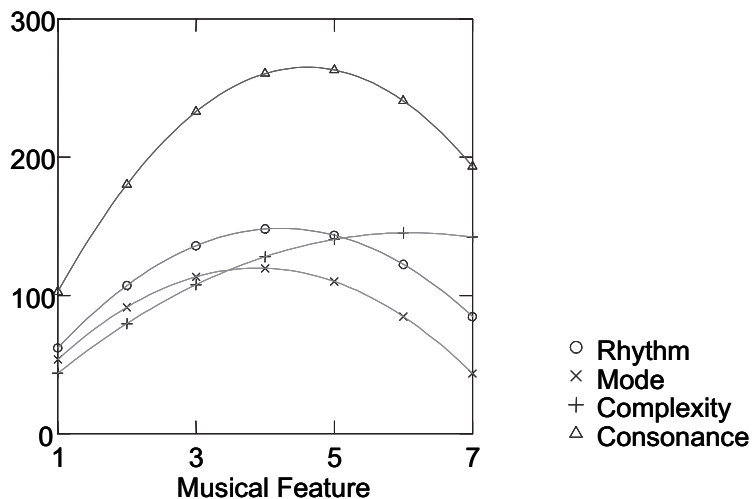

Skin conductance level (SCL)

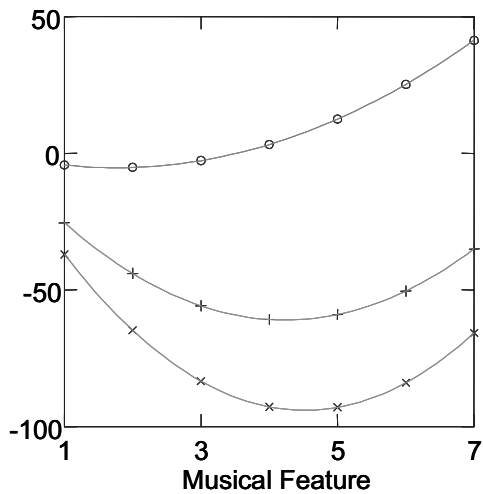

Rhythm

$\times$ Pitch level

+ Consonance

Figure 2. Significant quadratic relationships between musical features and inspiratory time (upper left), expiratory time (upper right), minute ventilation (lower left), and skin conductance level (lower right). The estimated models represented are presented in Table 5. For the physiological variables, data are (log stimulus interval- $\log$ baseline) $\times 1000$. Refer to Table 2 for the actual range of the musical features.

baseline (Gomez \& Danuser, 2004b). We have hypothesized that in perceptual contexts with minimal muscular activity, the relatively small changes in MV are preferentially achieved by changes in the time parameters rather than in the volume parameters (Gomez, Zimmermann, Guttormsen Schär, \& Danuser, 2005). We think that a correlation between $\mathrm{Vi}$ and musical determinants of arousal may be found in cases of intense physical activation. \%RC was found to increase with reports of arousal (Gomez \& Danuser, 2004a), yet, we did not find any correlation between \% RC and the musical features. This could indicate that changes in the thoracoabdominal breathing pattern were not directly determined by the structural properties of the music. Alternatively, it could be that we did not assess the musical features that are important for this variable. Louder music was associated with shorter Te and higher SCL. Wilson and Aiken (1977) did not find any effect of different sound levels of rock music on skin conductance. Because sound intensity is an important determinant of arousal reports (Schubert, 1999) and SCL increases with arousal, one would expect SCL to correlate with sound intensity. Future studies should elucidate this apparent inconsistency.
The analyses also revealed several quadratic relationships. In general, these indicate that the "extreme" levels of the musical feature were more closely associated with higher or lower physiological values than intermediate levels were. The validity and meaning of these quadratic relationships should be evaluated in future investigations

\section{Limitations and Outlook}

The use of real music means good ecological validity. However, it has the disadvantage that some musical features can correlate with each other. This makes impossible to disentangle their relative contributions to the observed relationships. This issue should be investigated by systematically varying the musical features in a factorial design (e.g., low, moderate, and high pitch level). A second limitation to be acknowledged is that instances of some musical factors were not represented (e.g., highly dissonant harmony). Thus, caution is needed in the interpretation of the relationships suggested by the estimated models outside the actual ranges. Another deficiency is represented by the rather simplistic 
analysis of some musical factors. For instance, harmony was only analyzed in terms of complexity and consonance, whereas more subtle aspects such as harmonic progressions were not considered. Although we assessed a quite large number of musical features, structural factors (e.g., timbre, musical form, rhythm patterns) that might be important determinants of the psychophysiological response to music were not evaluated. Furthermore, the genre of the musical selections was not homogenous, even though all excerpts were drawn from the corpus of Western music. The use of a unique musical genre would reduce individual differences in terms of musical preferences. A further step would be to use longer musical excerpts in order to take into account the dynamic nature of music. Music unfolds over time, and music's most expressive qualities probably relate to structural changes across time (e.g., accelerando to ritardando, transition from minor to major mode). One of the most influential theories of emotional effects of music has been Meyer's (1956) analysis of the affective reactions to the violation or confirmation of expectations with respect to the unfolding of musical structure in the course of the execution of a piece of music. In this vein, an area of empirical work is concerned with the temporal variation in perceived affects as related to local variation in the musical structure (e.g., Schubert, 1999). This research area could profit by including physiological measures to better understand the dynamic nature of the music-emotion system.

In order to elucidate how music is processed and experienced, it seems important to use multimethod approaches in which verbal reports are supplemented by neurophysiological and behavioral measures. The research presented here has provided a foundation on which future research could build.

\section{References}

Allesch, C. G. (1981). Untersuchungen zum Einfluss von Musik auf Pulsund Atemfrequenz [Studies on the influence of music on heart rate and respiratory rate]. Zeitschrift für Klinische Psychologie und Psychotherapie, 29, 353-382.

Baruch, C., \& Drake, C. (1997). Tempo discrimination in infants. Infant Behavior and Development, 20, 573-577.

Bradley, M. M., \& Lang, P. J. (1994). Measuring emotion: The selfassessment manikin and the semantic differential. Journal of Behavior Therapy and Experimental Psychiatry, 25, 49-59.

Byers, P. (1976). Biological rhythms as information channels in interpersonal communication behavior. In P. P. G. Bateson \& P. H. Klopfer (Eds.), Perspectives in ethology (pp. 135-164). New York: Plenum Press.

Campbell, I. G. (1942). Basal emotional patterns expressible in music. American Journal of Psychology, 55, 1-17.

Dalla Bella, S., Peretz, I., Rousseau, L., \& Gosselin, N. (2001). A developmental study of the affective value of tempo and mode in music. Cognition, 80, B1-B10.

Darner, C. L. (1966). Sound pulses and the heart. Journal of the Acoustical Society of America, 39, 414-416.

Destunis, G., \& Seebrandt, R. (1958). Beitrag zur Frage der Musikeinwirkung auf die zwischenhirngesteuerten Funktionen des Kindes [Contribution to the question about the effect of music on the functions of the diencephalan in the child]. In H. R. Teirich (Ed.), Musik in der Medizin (pp. 34-42). Stuttgart, Germany: Fischer Verlag.

Dowling, W. J., \& Harwood, D. L. (1986). Music cognition. New York: Academic Press.

Faith, M., \& Thayer, J. F. (2001). A dynamical systems interpretation of a dimensional model of emotion. Scandinavian Journal of Psychology, 42, 121-133.
Frank, C. (1982). Musikrhythmen als möglicher Synchronisator für biologische Rhythmen? [Musical rhythms as possible synchronizer of biological rhythms?] In G. Harrer (Ed.), Grundlagen der Musiktherapie und Musikpsychologie (pp. 85-104). Stuttgart, Germany: Fischer Verlag.

Gabrielsson, A. (2002). Emotion perceived and emotion felt: Same or different? Musicae Scientiae [Special issue 2001-2002], 123-147.

Gabrielsson, A., \& Juslin, P. N. (1996). Emotional expression in music performance: Between the performer's intention and the listener's experience. Psychology of Music, 24, 68-91.

Gabrielsson, A., \& Juslin, P. N. (2003). Emotional expression in music. In R. J. Davidson, K. R. Scherer \& H. H. Goldsmith (Eds.), Handbook of affective sciences (pp. 503-534). New York: Oxford University Press.

Gabrielsson, A., \& Lindström, E. (2001). The influence of musical structure on emotional expression. In P. N. Juslin \& J. A. Sloboda (Eds.), Music and emotion: Theory and research (pp. 223-248). London: Oxford University Press.

Gomez, P., \& Danuser, B. (2004a). Affective and physiological responses to environmental noises and music. International Journal of Psychophysiology, 53, 91-103.

Gomez, P., \& Danuser, B. (2004b). Attention please! How breathing facilitates attentive processing of visual and auditory stimuli [Abstract]. Psychophysiology, 41, S91.

Gomez, P., Stahel, W. A., \& Danuser, B. (2004). Respiratory responses during affective picture viewing. Biological Psychology, 67, 359-373.

Gomez, P., Zimmermann, P., Guttormsen Schär, S., \& Danuser, B. (2005). Respiratory responses associated with affective processing of film stimuli. Biological Psychology, 68, 223-235.

Haas, F., Distenfeld, S., \& Axen, K. (1986). Effects of perceived musical rhythm on respiratory pattern. Journal of Applied Physiology, 61, 11851191.

Harrer, G. (1982). Das Musikerlebnis im Griff des naturwissenschaftlichen Experiments [The musical experience studied through scientific experimentation]. In G. Harrer (Ed.), Grundlagen der Musiktherapie und Musikpsychologie (pp. 3-53). Stuttgart, Germany: Fischer Verlag.

Harrer, G., \& Harrer, H. (1968). Musik, Emotion und Vegetativum [Music, emotion, and the autonomic nervous system]. Wiener Medizinische Wochenschrift, 118, 966-971.

Hevner, K. (1937). The affective value of pitch and tempo in music. American Journal of Psychology, 49, 621-630.

Hodges, D. A. (1996). Human musicality. In D. A. Hodges (Ed.), Handbook of music psychology (pp. 29-68). San Antonio, TX: IMR Press.

Juslin, P. N. (1997). Perceived emotional expression in synthesized performances of a short melody: Capturing the listener's judgment policy. Musicae Scientiae, 1, 225-256.

Kleinen, G. (1968). Experimentelle Studien zum musikalischen Ausdruck [Experimental studies on musical expression]. Doctoral dissertation, Universität Hamburg, Germany.

Kneutgen, J. (1970). Eine Musikform und ihre biologische Funktion: Über die Wirkungsweise der Wiegenlieder [A musical form and its biological function: About the effect of lullabies]. Zeitschrift für Experimentelle Angewandte Psychologie, 17, 245-265.

Kölsch, S., Schroger, E., \& Gunter, T. C. (2002). Music matters: Preattentive musicality of the human brain. Psychophysiology, 39, 38-48.

Lang, P. J., Greenwald, M. K., Bradley, M. M., \& Hamm, A. O. (1993). Looking at pictures: Affective, facial, visceral, and behavioral reactions. Psychophysiology, 30, 261-273.

Meyer, L. B. (1956). Emotion and meaning in music. Chicago: University of Chicago Press.

Nyklíček, I., Thayer, J. F., \& Van Doornen, L. J. P. (1997). Cardiorespiratory differentiation of musically-induced emotions. Journal of Psychophysiology, 11, 304-321.

Oatley, K., \& Jenkins, J. M. (1996). Understanding emotions. Oxford, England: Blackwell. 
Rigg, M. G. (1964). The mood effects of music: A comparison of data from four investigators. Journal of Psychology, 58, 427-438.

Rosenfeld, A. H. (1985). Music, the beautiful disturber. Psychology Today, 19, 48-56.

Russell, J. A., \& Feldman Barrett, L. (1999). Core affect, prototypical emotional episodes, and other things called emotion: Dissecting the elephant. Journal of Personality and Social Psychology, 76, 805-819.

Schmidt, B. (1984). Empirische Untersuchung emotionaler Wirkungen verschiedener Tempi bei rhythmisch betonter Musik [Empirical investigation on the emotional effects of different tempi of rhythmically accentuated music]. Jahrbuch der deutschen Gesellschaft für Musikpsychologie, 1, 149-159.

Schubert, E. (1999). Measuring emotion continuously: Validity and reliability of the two dimensional emotion space. Australian Journal of Psychology, 51, 154-165.

Shrout, P. E., \& Fleiss, J. L. (1979). Intraclass correlations: Uses in assessing rater reliability. Psychological Bulletin, 86, 420-428.

Sloboda, J. A., \& Juslin, P. N. (2001). Psychological perspectives on music and emotion. In P. N. Juslin \& J. A. Sloboda (Eds.), Music and emotion: Theory and research (pp. 71-104). London: Oxford University Press.

Stern, D. (1985). The interpersonal world of the infant. A view from psychoanalysis and developmental psychology. New York: Basic Books.

Thompson, W. F., \& Robitaille, B. (1992). Can composers express emotions through music? Empirical Studies of the Arts, 10, 79-89.

Traxel, W., \& Wrede, G. (1959). Hautwiderstandsänderungen bei Musik- darbietungen [Changes in galvanic skin resistance during musical presentations]. Zeitschrift für Experimentelle \& Angewandte Psychologie, 6, 293-309.

Vaitl, D., Vehrs, W., \& Sternagel, S. (1993). Prompts-leitmotif-emotion: Play it again, Richard Wagner! In N. Birbaumer \& A. Öhman (Eds.), The structure of emotion: Psychophysiological, cognitive, and clinical aspects (pp. 169-189). Seattle, WA: Hogrefe \& Huber.

Watson, K. B. (1942). The nature and measurement of musical meanings. Psychological Monographs, 54, 1-43.

Wedin, L. (1972). A multidimensional study of perceptual-emotional qualities in music. Scandinavian Journal of Psychology, 13, 241-257.

Wilson, C. L., \& Aiken, I. S. (1977). The effect of intensity levels upon physiological and subjective affective response to rock music. Journal of Music Therapy, 14, 60-76.

Witvliet, C. V. O. (1998). The impact of music-prompted emotional valence and arousal on self-report, autonomic, facial EMG, and startle responses across experimental contexts. (UMI No. 9819062). Dissertation Abstracts International: Section B: The Sciences and Engineering. Vol. 58 (12-B), June 1998, p. 6832.

Zentner, M. R., \& Kagan, J. (1998). Infants' perception of consonance and dissonance in music. Infant Behavior \& Development, 21, 483-492.

Received January 23, 2006

Revision received September 7, 2006

Accepted September 28, 2006 